\title{
Effect of early weaning on the expression of excitatory amino acid transporter 1 in the jejunum and ileum of piglets
}

\author{
QIU-JU WANG ${ }^{1,2^{*}}$, YI-ZHE CUI ${ }^{2^{*}}$, XIU-YING ZHANG ${ }^{1}$ and JING $\mathrm{SU}^{3}$ \\ ${ }^{1}$ Department of Basic Veterinary Medicine, College of Veterinary Medicine, \\ Northeast Agricultural University, Harbin, Heilongiiang 150030; ${ }^{2}$ Department of Animal Medicine, \\ College of Animal Science and Veterinary Medicine, Heilongjiang Bayi Agricultural University, \\ Daqing, Heilongjiang 163319; ${ }^{3}$ Heilongjiang Province Animal Epidemic Prevention \\ and Control Center, Harbin, Heilongjiang 150069, P.R. China
}

Received March 28, 2016; Accepted May 2, 2017

DOI: $10.3892 / \mathrm{mmr} .2017 .7421$

\begin{abstract}
The present study aimed to compare the expression levels of excitatory amino acid transporters (EAATs) and growth status of piglets weaned at 10-20 days after birth with suckling piglets. A total of 40 hybrid piglets (Landrace x Large White $\mathrm{x}$ Duroc) born to 40 different sows, with similar body weight were selected for the present study. They were randomly divided into two groups ( $\mathrm{n}=20$ per group): Control group (suckling piglets) and experimental group (weaned piglets, reared in isolation). The experiment lasted for 10 days. At the end of the experiment, 12 piglets were randomly selected from each group and the jejunum and the ileum were collected in order to determine excitatory amino acid carrier 1 (EAAC1) expression levels and free amino acid content. The present study determined that early weaning significantly reduced EAAC1 gene and protein (57 and $73 \mathrm{kDa}$ ) expression levels and glutamate transporter associate protein 3-18 (GTRAP3-18; $50 \mathrm{kDa}$ ) in the jejunum and the ileum compared with the suckling group $(\mathrm{P}<0.05)$. Weaning led to an increased content of free glutamic acid (Glu) and total amino acids in the jejunum; however, content of free Glu and total amino acids in the ileum was significantly reduced $(\mathrm{P}<0.05)$. Early weaning reduced the expression of EAAC1 and GTRAP3-18, which was possibly due to the amino acid absorption and transport disorder in the small intestine due to the Glu deficiency.
\end{abstract}

Correspondence to: Dr Xiu-Ying Zhang, Department of Basic Veterinary Medicine, College of Veterinary Medicine, Northeast Agricultural University, 59 Mucai Street, Xiangfang, Harbin, Heilongjiang 150030, P.R. China

E-mail: zhxiuyingdr@163.com

*Contributed equally

Key words: piglet, weaning, excitatory amino acid transporter 1, small intestine

\section{Introduction}

Glutamic acid (Glu) is an important source of energy in the mucosa and the conditionally essential amino acid in early weaned piglets (1). Glu has an important function in the growth and repair of intestinal mucosa. The absorption of Glu in the intestine requires specific transporters. Excitatory amino acid transporters (EAATs) are $\mathrm{Na}^{+}$-dependent high-affinity Glu transporters (2), that maintain the Glu balance of the nervous system. Excitatory amino acid carrier 1 (EAAC1) belongs to EAAT family and its transport rate is $~ 10$ times of that of other transporters in the nervous system (3). EAAC1 is also expressed in other non-nervous tissues such as the small intestine. EAAC1 expression is negatively regulated by glutamate transporter associate protein 3-18 (GTRAP3-18). In various types of human cancer and epilepsy, GTRAP3-18 inhibits Glu transport via EAAC1 by binding to the C-terminal of EAAC1, leading to Glu poisoning in the nervous system (4). It is of note that, GTRAP3-18 may bind specifically to EAAC1 although not to other EAATs (5). EAAC1 expression is associated with the expression of GTRAP3-18. Previous studies have focused on EAAC1 in the nervous system as opposed to the intestine $(6,7)$. A previous study determined that deletion of the $E A A C l$ gene may lead to the loss of age-dependent dopaminergic neurons and an increase in oxidative stress in mice (8). In patients with Alzheimer's disease, abnormal EAAC1 accumulation was located in the hippocampal neurons (9). Fu et al (10) cloned the jejunal EAAC1 protein in suckling piglets and investigated the dynamic changes of EAAC1 protein expression, which was low in the ileum of piglets with low birth weight (10). These previous findings imply that EAAC1 expression may be associated with abnormal development or the stress and disease status of the piglets. Low EAAC1 expression may reduce the transport rate of Glu and impair development and absorption function of the mucosa in piglets (10). Weaning induces stress piglet stress and the uptake of maternal Glu is interrupted. The present study aimed to investigate the changes of the expression levels of EAAC1 and its regulatory protein GTRAP3-18 in the jejunum and ileum of weaned piglets. The effect of weaning on EAAC1 expression was analyzed; therefore, providing insight into the underlying molecular mechanism of intestinal mucosa 
repair and potential measures that may be implemented in order to improve the growth performance of weaned piglets.

\section{Materials and methods}

Grouping and feeding management. The experiment was performed at Pig Breeding Demonstration Base (Qiqihar, China) in May 2010. A total of 40 hybrid piglets (Landrace x Large White x Duroc) born to 40 different sows, with similar body weight were selected. A single-factor experiment design was adopted. The piglets were randomly divided into two groups ( $\mathrm{n}=20$ per group): Control group (suckling piglets) and experimental group (weaned piglets, reared in isolation). The experiment continued for 10 days once the piglets were 10 days old.

The suckling piglets were reared by sows in the piglet house for the first 10 days of life. Following this, the weaned piglets were then reared in a nursery piglet house for a further 10 days. Weaned piglets were fed with corn-soybean meal-based starter diet for 10 days, 3 times daily (morning, noon and evening), and allowed free access to water. Each weaned piglet was fed in a separate cage and the quantity of food consumed by each weaned piglet (the feed-to-gain ratio) was calculated by weighing the amount of food originally provided and the amount of food leftover each morning. The weaned piglets were weighed on the first day they were fed separately (10 days old) and on the last day when the study was complete (20 days old). The composition and the nutrition of the basal diet are presented in Table I.

The nursery piglet house provided a closed environment with good ventilation and cement flooring. Segregated early weaning (SEW) was adopted with 1 piglet per pen. An infrared heat lamp was hung $0.8 \mathrm{~m}$ above the ground at the corner of the pen. The ground directly under the lamp was paved with a $0.5 \times 1 \mathrm{~m}$ heat-absorbing pad to ensure the warmth of the piglets. The present study was approved by the Ethics Committee of Northeast Agricultural University (Harbin, China) (approval no. SYXK (Hei) 2012-2067).

Sample collection and processing. On the morning of the 11th day, 12 piglets were randomly selected from each group $(n=24)$. Piglets were sedated and maintained under anesthesia by inhalation of $8 \%$ anesthetic isoflurane via a facial mask. The abdominal cavity was opened to harvest the jejunum and ileum, which were washed with ice-cold normal saline. Samples were collected from the middle of the intestine and preserved in liquid nitrogen, as previously described (5). The samples were ground with liquid nitrogen to powder using a mortar and subsequently preserved at $-80^{\circ} \mathrm{C}$. At the end of tissue sampling, piglets were euthanized via an intra-cardiac injection of $50 \mathrm{mg} / \mathrm{kg}$ sodium pentobarbital (Schering-Plough Canada, Inc., Pointe-Claire, QC, Canada) (11).

Sample preparation. Cryopreserved homogenate small intestine sample weighing $\sim 1.3 \mathrm{~g}$ was used and mixed with homogenate buffer (50 mM D-mannitol, $10 \mathrm{mM} \mathrm{HEPES}$ and $2.0 \mu \mathrm{g} \cdot \mathrm{ml}^{-1}$ each of aprotinin, leupetin, pepstatin A, N-tosyl-L-phenylalanine chloromethyl-ketone, N-a-p-tosyl-L-lysine ketone and $0.20 \mathrm{mM}$ PMSF, pH 7.4; all Sigma; Merck KGaA, Darmstadt, Germany) at the proportion of $1 \mathrm{~g} / 20 \mathrm{ml}$. Subsequently, the sample was thawed in the homogenate buffer containing the protease inhibitor. The sample was homogenized using a multi-layer homogenizer at $1,523 \mathrm{x}$ g for $3 \mathrm{~min}$ at $4^{\circ} \mathrm{C}$ (with a $\sim 20 \mathrm{sec}$ pause every $\mathrm{min}$ ). The homogenate was weighed and the total volume was recorded with $2 \mathrm{ml}$ cryopreserved at $-80^{\circ} \mathrm{C}$. The endoplasm sample was prepared by $\mathrm{Mg}^{2+}$ precipitation and differential centrifugation at $4^{\circ} \mathrm{C}$ as previously described (5). The remaining endoplasm sample was used for further differential centrifugation to obtain the apical membrane of the cells. Briefly, the remaining supernatant was mixed with $1 \mathrm{M} \mathrm{MgCl}_{2}$ to produce $10 \mathrm{mM} \mathrm{MgCl}_{2}$, stirred on ice for $15 \mathrm{~min}$ and then centrifuged at $4^{\circ} \mathrm{C}$ and $2,400 \mathrm{x}$ g for $15 \mathrm{~min}$. After discarding the top foam layer, the resultant supernatant was centrifuged at $4^{\circ} \mathrm{C}$ and 19,000 $\mathrm{x}$ g for $30 \mathrm{~min}$ using the Ti 55.2 rotor on a Beckman L8-55 Ultracentrifuge to generate crude apical membrane pellets. The supernatant obtained was regarded as the cytosolic fraction and sampled for protein content analyses as well as western blotting analyses of the abundance of target proteins. The crude apical membrane pellets were then suspended in $15 \mathrm{ml}$ of membrane suspension buffer (300 mM D-mannitol, $25 \mathrm{mM}$ HEPES and $2.0 \mu \mathrm{g} \cdot \mathrm{ml}^{-1}$ each of aprotinin, leupetin, pepstatin A, N-tosyl-L-phenylalanine chloromethyl-ketone, $\mathrm{N}$ - $\alpha$-p-tosyl-L-lysine ketone and 0.20 mM PMSF, pH 7.4) and centrifuged at $4^{\circ} \mathrm{C}$ and $39,000 \times \mathrm{g}$ for $30 \mathrm{~min}$ to generate the final apical membrane vesicle pellets. The final pellets were re-suspended with a 25-gauge needle in $5 \mathrm{ml}$ of the same membrane suspension buffer to yield the apical membrane fraction samples for protein content and western blotting analyses.

Detection of EAATs expression levels. The protein concentration assay was performed with PMSF buffer (Sigma; Merck $\mathrm{KGaA}$ ) as previously described (6). Protein in the homogenate, endoplasm and apical membrane of the cells was quantified using a Bradford assay dye reagent (Bio-Rad Laboratories, Inc., Hercules, CA, USA) and proteins in fetal bovine serum (grade IV) as the standard. A total of $20 \mu \mathrm{g}$ protein/lane was loaded and separated on a $10 \%$ SDS-PAGE gel.

Western blotting. Western blotting was performed using $1 \mu \mathrm{g} / \mu \mathrm{l}$ protein sample and $\beta$-actin as the internal control. Proteins were transferred to PVDF membranes, which were blocked at room temperature for $1 \mathrm{~h}$ with $6 \%$ non-fat dry milk powder dissolved in 1X TBS (25 mM Tris- $\mathrm{HCl}, 0.15 \mathrm{M} \mathrm{NaCl}, \mathrm{pH} 7.4$ ) and then incubated at $4^{\circ} \mathrm{C}$ with primary antibodies overnight. The primary antibody for EAAC1 was goat anti-human EAAC1 polyclonal antibody (cat. no. sc-7761; Santa Cruz Biotechnology, Inc., Dallas, TX, USA) diluted to 1:2,000, the primary antibody for GTRAP3-18 was mouse anti-human GTRAP3-18 polygonal antibody (cat. no. H00010550-A01; Abnova, Atlanta, GA, USA) diluted to 1:2,000; primary antibody to $\beta$-actin was mouse anti-human monoclonal antibody (cat. no. VMA00014; Bio-Rad Laboratories, Inc.) diluted to $1: 10,000$. The membranes were then incubated at room temperature for $1 \mathrm{~h}$ with the purified secondary antibody rabbit anti-human IgG (cat. no. STAR195; Bio-Rad Laboratories, Inc.) diluted to $1: 10,000$.

Detection of gene expression. The primers for the target genes and the housekeeping gene were designed using Primer 
Table I. Weaning diet of piglets used in the present study (dry basis).

\begin{tabular}{lc} 
A, Contents & \\
\hline Ingredient & Quantity (\%) \\
\hline Lactose & 15 \\
Glucose & 8.52 \\
Corn & 15.95 \\
Soybean & 56.00 \\
L-threonine & 0.00 \\
Corn oil & 0.8 \\
Limestone & 1.05 \\
CaHPO & 1.58 \\
Iodized salt & 0.5 \\
Vitamin-mineral premix & 0.5 \\
Lincomycin antibiotic & 0.1 \\
\hline
\end{tabular}

\section{B, Nutrition}

\begin{tabular}{lc}
\hline Ingredient & Quantity \\
\hline $\mathrm{CP}(\%)$ & 26.0 \\
$\mathrm{DE}(\mathrm{MJ} / \mathrm{kg})$ & 14.27 \\
$\mathrm{P}(\%)$ & 0.92 \\
$\mathrm{Ca}(\%)$ & 0.68 \\
Ca:P & 0.74 \\
Arginine $(\mathrm{mg} / \mathrm{kg})$ & 1.87 \\
Histidine $(\mathrm{mg} / \mathrm{kg})$ & 0.69 \\
Isoleucine $(\mathrm{mg} / \mathrm{kg})$ & 1.16 \\
Leucine $(\mathrm{mg} / \mathrm{kg})$ & 2.07 \\
Lysine $(\mathrm{mg} / \mathrm{kg})$ & 1.63 \\
Methionine $(\mathrm{mg} / \mathrm{kg})$ & 0.37 \\
Cysteine $(\mathrm{mg} / \mathrm{kg})$ & 0.42 \\
Phenylalanine $(\mathrm{mg} / \mathrm{kg})$ & 1.28 \\
Tyrosine $(\mathrm{mg} / \mathrm{kg})$ & 0.99 \\
Threonine $(\mathrm{mg} / \mathrm{kg})$ & 1.02 \\
Tryptophan $(\mathrm{mg} / \mathrm{kg})$ & 0.35 \\
Valine $(\mathrm{mg} / \mathrm{kg})$ & 1.22 \\
\hline
\end{tabular}

Premier version 5.0 software (Premier Biosoft International, Palo Alto, CA, USA) based on GenBank cDNA sequences (Table II). The primers were synthesized by Invitrogen; Thermo Fisher Scientific, Inc. (Waltham, MA, USA). To avoid contamination of the primers by non-specific genomic DNA, mRNA sequences from all samples were aligned against the pig genome using Spidey v0.7 software (now Splign software; https://www.ncbi.nlm.nih.gov/sutils/splign/splign.cgi). Each primer contained 2 exons. Total RNA was extracted from the samples using TRIzol (Invitrogen; Thermo Fisher Scientific, Inc.) as previously described (6). Following digestion with DNA enzyme (Invitrogen; Thermo Fisher Scientific, Inc.), cDNA synthesis was performed using iScript cDNA synthesis kit (Bio-Rad, Laboratories, Inc.) according to the manufacturer's protocol. Quantitative polymerase chain reaction
(qPCR) was performed using iQ SYBR-Green supermix (Qiagen, Inc., Valencia, CA, USA) with total reaction volume of $25 \mu \mathrm{l}$. The procedures of reverse transcription (RT)-qPCR were as follows: RT at $50^{\circ} \mathrm{C}$ for $30 \mathrm{~min}$, denaturation at $95^{\circ} \mathrm{C}$ for $15 \mathrm{~min}$, amplification and quantification for 45 cycles, denaturation at $95^{\circ} \mathrm{C}$ for $15 \mathrm{sec}$, annealing at $54^{\circ} \mathrm{C}$ for $15 \mathrm{sec}$, extension at $72^{\circ} \mathrm{C}$ for $15 \mathrm{sec}$; plotting of dissociation curve, $60-99^{\circ} \mathrm{C}$, temperature rise at $0.1^{\circ} \mathrm{C} / \mathrm{sec}$, with fluorescence detection. The relative expression ratio of target gene to the housekeeping gene was calculated as follows:

\section{$\mathrm{R}=2-\mathrm{Cq}$ (target gene-housekeeping gene) (12)}

where $\mathrm{R}$ is relative expression ratio of the target gene; $\mathrm{Cq}$ is the quantification cycle value. Under this threshold cycle value, the target gene and the $\beta$-actin housekeeping gene were amplified by over 30 fluorescence units. The optimal RT-qPCR efficiency was obtained from the formula of $-1+10$ (-1/slope) with serial dilution of RNA. The efficiency was consistent for the target gene and $\beta$-actin. Experiments were repeated three times with three duplicates of each.

Quantification of free amino acids in the small intestine of piglets. High-performance liquid chromatography (HPLC) was performed as previously described (13). Briefly, HPLC was performed using the LC-9A liquid chromatograph system (Shimadzu Corporation, Kyoto, Japan). The analytical column Inertsil ODS-2 (150x4.6 mm ID 51m; GL Sciences, Inc., Tokyo, Japan) was fixed at $40^{\circ} \mathrm{C}$ and connected through a corresponding guard column (10x4.0 mm ID 5 1m; GL Sciences, Inc.) with a HPLC workstation; the flow rate of the eluate was $1.0 \mathrm{ml} / \mathrm{min}$. All samples were injected into the column with an Auto Injector (Shimadzu Corporation). An RF-530 fluorescence spectromonitor (Shimadzu Corporation) was used with excitation and emission set at 380 and $510 \mathrm{~nm}$, respectively. The signals from the detector were recorded on a Chromatopac C-R4A (Shimadzu Corporation). O-phthalaldehyde was used as an internal standard.

Statistical analysis. The protein expression levels were expressed relative to the expression levels of the EAAC1 and GTRAP3-18 genes. The protein blots were scanned and analyzed using Quantity One software v19.0 (Bio-Rad Laboratories, Inc.). The optical density was calculated. The relative expression of the target protein was characterized as the optical density ratio of the target gene to $\beta$-actin. One-way analysis of variance was performed using SAS version 9.2 (SAS Institute, Inc., Cary, NC, USA). Data were expressed as the mean \pm standard deviation. $\mathrm{P}<0.05$ was considered to indicate a statistically significant difference. The findings of the present study were plotted as histograms and curves using The Scientific Fig. Processor software (Fig. P Software Incorporated, Hamilton, ON, Canada).

\section{Results}

Effect of weaning on growth performance. Weaned piglets were fed $148.50 \pm 16.90 \mathrm{~g} / \mathrm{day}(\mathrm{n}=20)$ with feed-to-gain ratio of $3.58 \pm 2.34$ during the experiment. The weaned piglets showed had significantly reduced body weight at the end of the 
Table II. Primer sequences and product size.

\begin{tabular}{lllll}
\hline Gene & \multicolumn{1}{c}{ Forward $\left(5^{\prime} \rightarrow 3^{\prime}\right)$} & \multicolumn{1}{c}{ Reverse $\left(5^{\prime} \rightarrow 3^{\prime}\right)$} & Size (bp) & GenBank no. \\
\hline EAAC1 & CAAACTGGGCCTTTACATGG & TGTTGCTGAACTGGAGGAGA & 169 & AY195622 \\
GTRAP3-18 & CTGGTATTCACGGGCTTTGT & CCCCCAAACATGGATATGAG & 131 & NM_001048073 \\
$\beta$-actin & GGATGCAGAAGGAGATCACG & ATCTGCTGGAAGGTGGACAG & 150 & AY550069
\end{tabular}

EAAC1, excitatory amino acid carrier 1; GTRAP3-18, glutamate transporter associate protein 3-18.

experiment, compared with the suckling piglets $(\mathrm{P}<0.05)$ and the daily weight gain of the weaned piglets was also significantly lower $(\mathrm{P}<0.001$; Table III). Therefore, early weaning had a negative impact on the growth performance of piglets.

Effect of weaning on EAAC1 protein expression. EAAC1 protein content was detected in the homogenate, endoplasm and apical membrane of the small intestine using western blotting. The molecular weight of the EAAC1 was $57 \mathrm{kDa}$ in the homogenate and endoplasm and $73 \mathrm{kDa}$ in the apical membrane of the cells. With $\beta$-actin as the internal control, the EAAC1 protein expression in the homogenate, endoplasm and apical membrane of the jejunum was significantly reduced, by 25,21 and $9 \%$, respectively $(\mathrm{P}<0.05$; Fig. 1$)$. The EAAC1 protein expression in the homogenate, endoplasm and apical membrane of the ileum was also significantly reduced, by 32, 22 and 14\%, respectively $(\mathrm{P}<0.05$; Fig. 2$)$. Therefore, EAAC1 protein was expressed in the small intestine of piglets, and its expression levels were reduced following early weaning.

Effect of early weaning on EAAC1 mRNA expression. EAAC1 mRNA expression was compared between the suckling piglets and the weaned piglets, as presented in Table IV. $\beta$-actin was used as an internal reference, the EAAC1 mRNA expression in the jejunum of the weaned piglets decreased by $88 \%$ as compared with the suckling piglets $(\mathrm{P}<0.05)$; the EAAC1 mRNA expression in the ileum of the weaned piglets decreased by $73 \%(\mathrm{P}<0.05)$.

Correlations of EAAC1 protein and $m R N A$ expression levels in different parts of the small intestine. Pearson's correlation was used to determine that the EAAC1 protein and mRNA expression levels in the homogenate $(\mathrm{r}=0.52 ; \mathrm{P}=0.042 ; \mathrm{n}=24)$, endoplasm $(\mathrm{r}=0.56 ; \mathrm{P}=0.021 ; \mathrm{n}=24)$ and apical membrane of cells $(\mathrm{r}=0.49 ; \mathrm{P}=0.008 ; \mathrm{n}=24)$ in the jejunum were positively correlated for weaned and suckling piglets. Additionally, the EAAC1 protein expression in the homogenate of the jejunum was positively correlated with the endoplasm of the jejunum. The EAAC1 protein expression in the endoplasm of the jejunum was positively correlated with that in the apical membrane of the cells for weaned and suckling piglets. The EAAC1 mRNA and protein expression levels in the homogenate $(\mathrm{r}=0.51 ; \mathrm{P}=0.021 ; \mathrm{n}=24)$, endoplasm $(\mathrm{r}=0.51 ; \mathrm{P}=0.016$; $\mathrm{n}=24)$ and apical membrane of cells $(\mathrm{r}=0.41 ; \mathrm{P}=0.016 ; \mathrm{n}=24)$ in the ileum were positively correlated for weaned and suckling piglets. EAAC1 protein expression in the homogenate of ileum was positively correlated with that in the endoplasm of
Table III. Effect of weaning on growth performance of piglets.

\begin{tabular}{lcrr}
\hline Characteristic & Suckling & Weaning & SEM \\
\hline Initial body weight $(\mathrm{kg})$ & 4.18 & 4.77 & 0.16 \\
Terminal body weight $(\mathrm{kg})$ & 7.68 & $5.19^{\mathrm{a}}$ & 0.24 \\
Average daily gain (g/day) & 350 & $41.50^{\mathrm{b}}$ & 24.49 \\
Average daily food intake (g/day) & - & 148.50 & 16.90 \\
ADFI/ADG (g/g) & - & 3.58 & 2.34 \\
\hline
\end{tabular}

Data are presented as mean $\pm \mathrm{SEM}, \mathrm{n}=20 .{ }^{\mathrm{a}} \mathrm{P}<0.05,{ }^{\mathrm{b}} \mathrm{P}<0.01$ vs. the suckling group. SEM, standard error of the mean.

the ileum. The EAAC1 protein expression in the endoplasm of ileum was positively correlated with that in the apical membrane of the cells $(\mathrm{P}<0.05)$ for weaned and suckling piglets.

Effect of early weaning on GTRAP3-18 protein expression. The molecular weight of GTRAP3-18 in the homogenate, endoplasm and apical membrane of cells in the jejunum and ileum was $50 \mathrm{kDa}$, as presented in Figs. 3 and 4. $\beta$-actin was used as an internal reference and the GTRAP3-18 protein expression in the homogenate, endoplasm and apical membrane of the jejunum of the weaned piglets was reduced by 15,28 and $55 \%$ when compared with the suckling piglets $(\mathrm{P}<0.05$; Fig. 3). The GTRAP3-18 protein expression in the homogenate, endoplasm and apical membrane of the ileum was also significantly reduced by 16,7 and $27 \%$, respectively $(\mathrm{P}<0.05$; Fig. 4).

Effect of early weaning on GTRAP3-18 mRNA expression. The GTRAP3-18 mRNA expression levels in the small intestine of the weaned piglets and suckling piglets are presented in Table V. With $\beta$-actin as internal reference, the GTRAP3-18 mRNA expression in the jejunum of the weaned piglets was reduced by $70 \%$ compared with the suckling piglets $(\mathrm{P}<0.05)$ and expression in the ileum of the weaned piglets was reduced by $52 \%(\mathrm{P}<0.05)$.

Correlations of GTRAP3-18 expression levels in different parts of the small intestine. Pearson's correlation revealed that the GTRAP3-18 protein and mRNA expression levels in the homogenate $(r=0.33 ; \mathrm{P}=0.027 ; \mathrm{n}=24)$, endoplasm $(\mathrm{r}=0.54$; $\mathrm{P}=0.019 ; \mathrm{n}=24)$ and apical membrane of cells $(\mathrm{r}=0.56$; $\mathrm{P}=0.028 ; \mathrm{n}=24)$ in the jejunum were positively linearly 

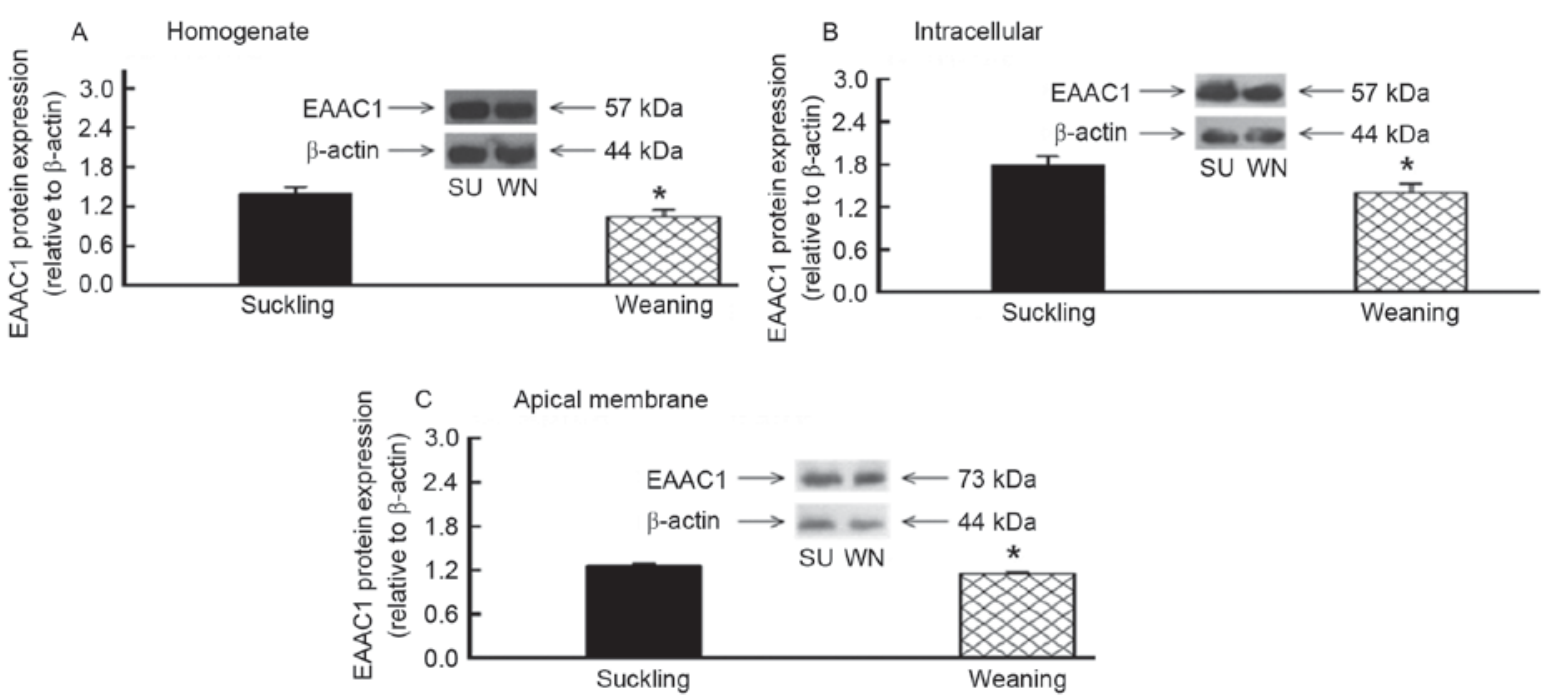

Figure 1. EAAC1 protein expression levels in the (A) homogenate (B) intracellular and (C) apical membrane of jejunum in piglets. " $\mathrm{P}<0.05$ vs. suckling. SU, suckling; WN, weaning; EAAC1, excitatory amino acid carrier 1.
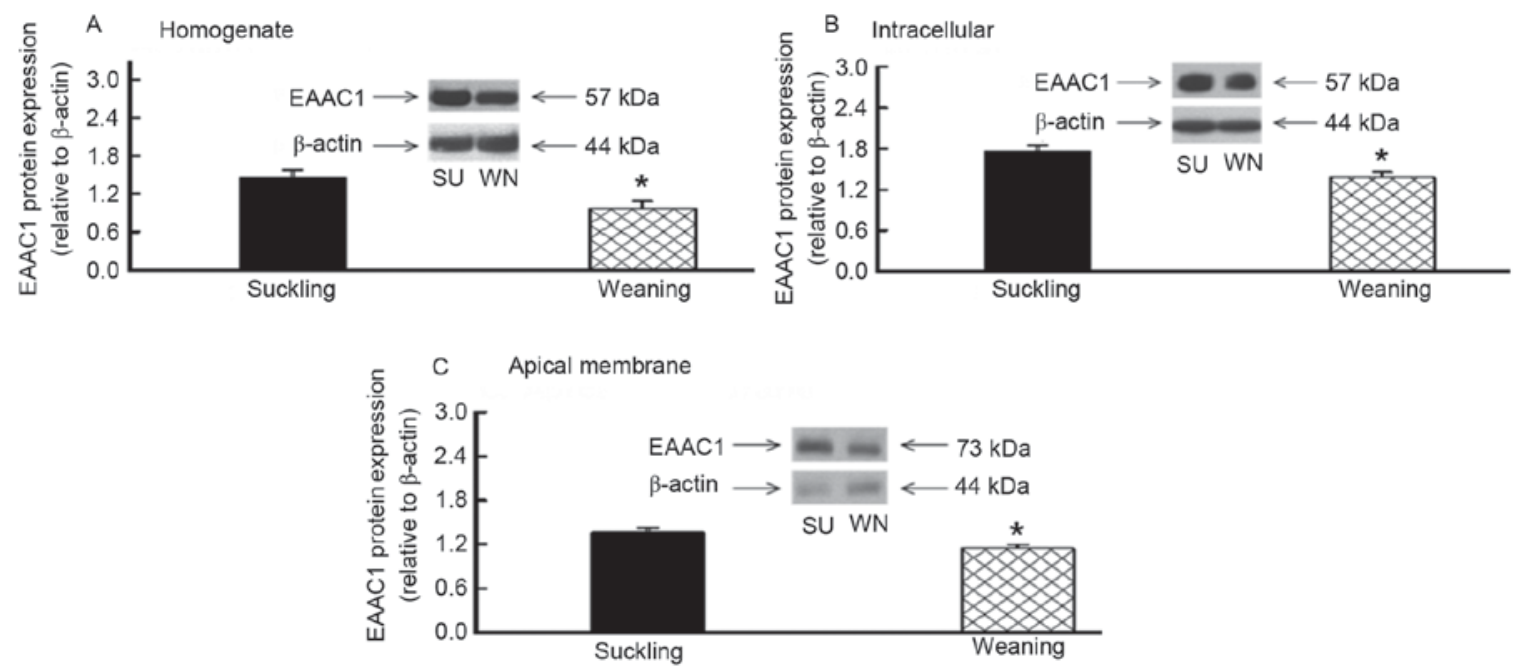

Figure 2. EAAC1 protein expression levels in the (A) homogenate (B) intracellular and (C) apical membrane of ileum in piglets. "P<0.05 vs. suckling. SU, suckling; WN, weaning; EAAC1, excitatory amino acid carrier 1.

correlated for weaned and suckling piglets. Additionally, the GTRAP3-18 protein expression in the homogenate of the jejunum was positively correlated with that in the endoplasm and apical membrane of the jejunum. The GTRAP3-18 protein expression in the endoplasm of the jejunum was positively correlated with that in the apical membrane of the cells $(\mathrm{P}<0.05)$ for weaned and suckling piglets. The GTRAP3-18 protein and mRNA expression in the homogenate $(\mathrm{r}=0.42 ; \mathrm{P}=0.014 ; \mathrm{n}=24)$, endoplasm $(\mathrm{r}=0.42 ; \mathrm{P}=0.047$; $\mathrm{n}=24)$ and apical membrane of cells $(\mathrm{r}=0.15 ; \mathrm{P}=0.029 ; \mathrm{n}=24)$ in the ileum were positively linearly correlated $(\mathrm{P}<0.05)$ for weaned and suckling piglets. GTRAP3-18 protein expression in the homogenate of ileum was positively correlated with that in the endoplasm and apical membrane of the ileum. The GTRAP3-18 protein expression in the endoplasm of ileum was positively linearly correlated with that in the apical membrane of the cells $(\mathrm{P}<0.05)$ for the weaned and suckling piglets.
Effect of early weaning on free amino acid content in the jejunum. Compared with the suckling piglets, The Glu content in the jejunum was significantly greater in the weaned piglets compared with the suckling piglets (by 26\%; $\mathrm{P}<0.05$; Fig. 5). However, no significant difference was identified between the content of glutamine (Gln), the substrate for the ASC amino-acid transporter 2 (ASCT2) protein in the weaned and suckling piglets. The contents of other free amino acids, including threonine, glycine and ornithine, increased by 57,88 and $53 \%$, respectively $(\mathrm{P}<0.05$; Fig. 5).

Effect of early weaning on free amino acid content in the ileum. The changes of the free amino acid content in the ileum of the weaned piglets and the suckling piglets were opposite to those observed in the jejunum. The Glu content, the substrate for the EAAC1 protein, were reduced by $43 \%$ in the weaned piglets $(\mathrm{P}<0.05)$. However, the content of $\mathrm{Gln}$, the substrate for the ASCT2 protein, was reduced by $52 \%$ in the weaned piglets 
Table IV. Intestinal excitatory amino acid carrier $1 \mathrm{mRNA}$ levels (relative to $\beta$-actin) in piglets.

\begin{tabular}{lccc}
\hline Location & Suckling & Weaning & SEM \\
\hline Jejunum & 0.0201 & $0.0024^{\mathrm{a}}$ & 0.0026 \\
Ileum & 0.0179 & $0.0048^{\mathrm{a}}$ & 0.0026 \\
\hline
\end{tabular}

Data are presented as mean $\pm \mathrm{SEM}, \mathrm{n}=12 .{ }^{\mathrm{a}} \mathrm{P}<0.05$ vs. the suckling group. SEM, standard error of the mean.

Table V. Intestinal glutamate transporter associate protein 3-18 mRNA levels (relative to $\beta$-actin) in piglets.

\begin{tabular}{lccc}
\hline Location & Suckling & Weaning & SEM \\
\hline Jejunum & 0.0067 & $0.0020^{\mathrm{a}}$ & 0.001 \\
Ileum & 0.0056 & $0.0027^{\mathrm{a}}$ & 0.0007
\end{tabular}

Data are presented as mean $\pm \mathrm{SEM}, \mathrm{n}=12$. ${ }^{\mathrm{a}} \mathrm{P}<0.05$ vs. the suckling group. SEM, standard error of the mean.

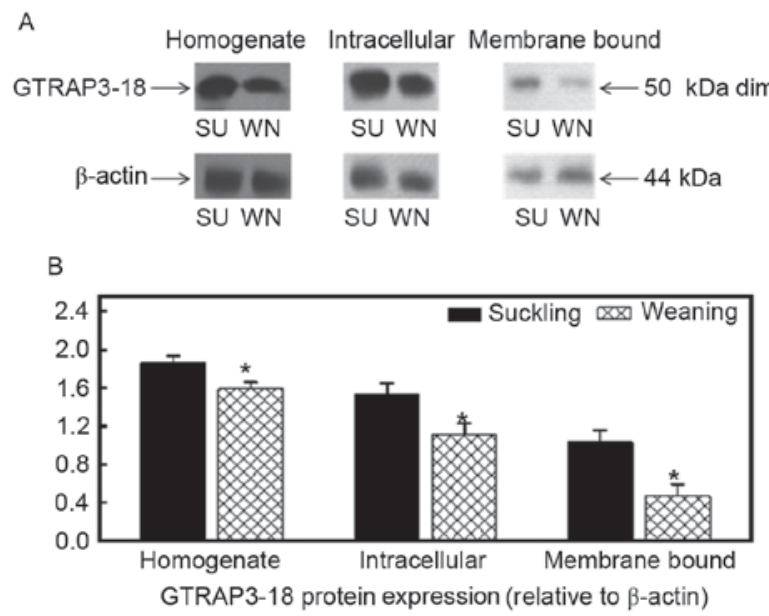

Figure 3. GTRAP3-18 protein expression in the jejunum of piglets was determined using (A) western blotting. (B) Quantification of western blotting. ${ }^{*} \mathrm{P}<0.05$ vs. suckling. SU, suckling; WN, weaning; GTRAP3-18, glutamate transporter associate protein 3-18.

$(\mathrm{P}<0.05)$. The contents of the remaining free amino acids, including lysine, methionine, phenylalanine, trypophan, arginine, taurine and tyrosine, were all reduced by $>42 \%(\mathrm{P}<0.05$; Fig. 6).

\section{Discussion}

Weaning may induce a series of changes in the morphology of piglets, including nutritional level, digestion and metabolism (14), stress, neuroendocrine (15) and gene functions. Daily weight gain following weaning is an important apparent indicator of the piglet's growth. If the daily weight gain does not change considerably after weaning as compared with the suckling piglets, this means that the daily diet had sufficient

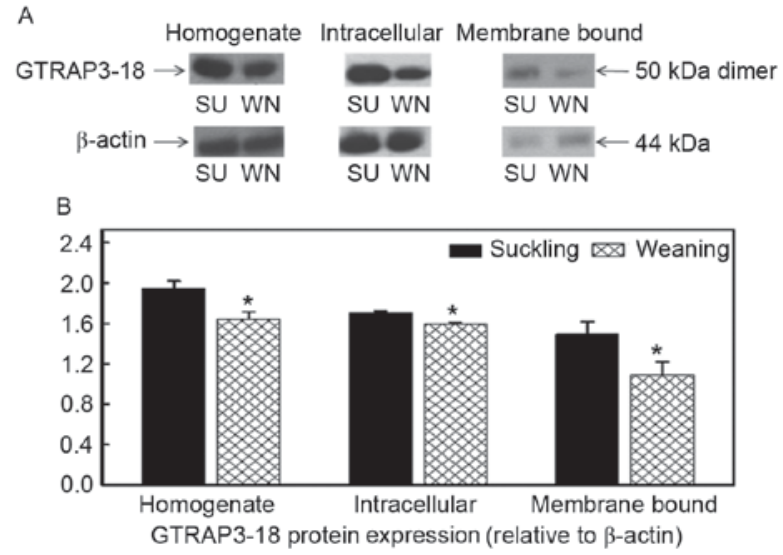

Figure 4. GTRAP3-18 protein expression in the ileum of piglets. was determined using (A) western blotting. (B) Quantification of western blotting. ${ }^{*} \mathrm{P}<0.05$ vs. suckling. SU, suckling; WN, weaning; GTRAP3-18, glutamate transporter associate protein 3-18.

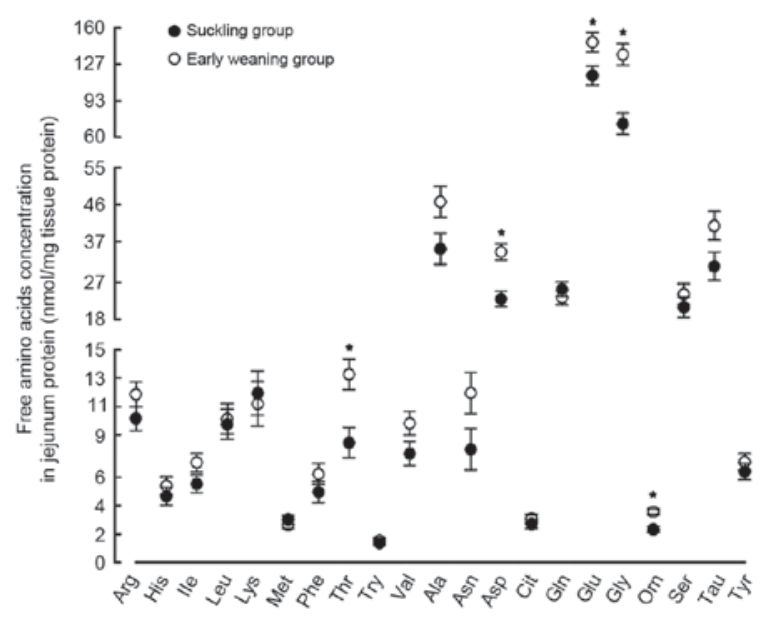

Figure 5. Effect of weaning on free amino acid content in the jejunum of piglets. ${ }^{~} \mathrm{P}<0.05$ vs. suckling.

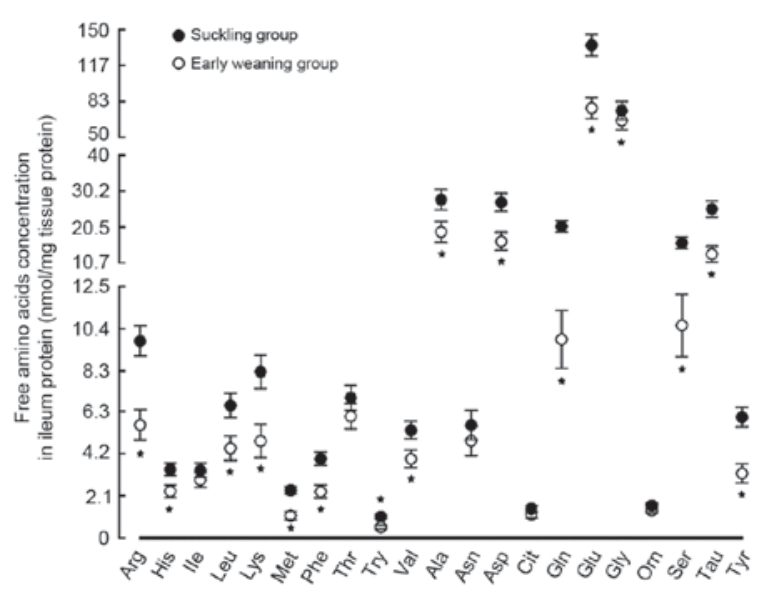

Figure 6. Effect of weaning on free amino acid content in the ileum of piglets. ${ }^{*} \mathrm{P}<0.05$ vs. suckling.

nutrients for the piglets and they have adapted to weaning with normal intestinal development. However, in practice, $\sim 10 \%$ of the weaned piglets die from physiological stress of two major 
sources, the change of the external environment and abnormal intestinal mucosa development due to a novel feeding diet. Weaning may induce changes of gastrointestinal functions and affects the regulation of gut-brain axis (16). The quantity of feed consumed by the piglets frequently decreases following weaning due to changes in nutrition and environment. The gastrointestinal tract is underdeveloped in piglets and weaning may lead to a decline in their growth performance. In the present study, the piglets in SEW treatment group exhibited signs of weaning-associated stress. The daily feeding quantity was $148.5 \mathrm{~g}$, which was lower compared with the standard of $240 \mathrm{~g} /$ day in the requirements of swine from the National Research Council (NRC). Additionally, the daily weight gain of the weaned piglets was significantly lower compared with the suckling piglets of the same age $(\mathrm{P}<0.001) . \mathrm{Gu}$ et al $(17)$ determined that weaning-associated stress may lead to significant structural and functional changes of the intestine, thus affecting the normal growth of piglets.

EAAC1 is a crucial Glu transporter with wide distribution in the entire cell body. A previous study (6) focused on Glu transport by EAAC1 in the central nervous system as opposed to the intestinal mucosa of piglets. The present study detected the EAAC1 protein and mRNA expression levels were significantly reduced in the intestine of weaned piglets compared with the suckling piglets. Watabe et al (18) revealed that GTRAP3-18 was a negative regulator of EAAC1 and intracellular glutathione content using HEK293 cells (18). Additionally, GTRAP3-18 had a sequential impact on the susceptibility to oxidative stress. Differentiation, heat stress and oxidative stress may also lead to the separation of GTRAP3-18 protein (6). This involves the upregulation of GTRAP3-18 protein or mRNA expression in response to oxidative stress. The present study determined that early weaning reduced the protein and mRNA expression of GTRAP3-18 in piglets, which was contrary to the response to heat and oxidative stress. In order to manage the increased stress, the piglets require more Glu from their daily diet for intestinal mucosa repair. The findings of a previous study revealed that the increased efficiency of Glu uptake may led to the downregulation of GTRAP3-18 protein expression levels (18). Increased Glu content in the jejunum led to reduced GTRAP3-18 protein expression in the jejunum, which was in accordance with previous findings by Lin et al (19). However, the Glu content and GTRAP3-18 expression in the ileum was reduced in weaned piglets. The function of GTRAP3-18 in stress and disease of piglets remains to be fully elucidated (5).

Glu is the excitatory amino acid transported by EAAC1. The present study determined that weaning led to a reduction in the content of free amino acids in the ileum and an increase of free amino acids in the jejunum of the weaned piglets. Previous studies revealed that EAAC1 was primarily expressed in the jejunum (20) and the efficiency of Glu transmembrane transport in the intestine was regulated by EAAC1 (21). Therefore, it is possible that the Glu transport efficiency was increased in the jejunum of weaned piglets in order to compensate for the reduced Glu uptake. In the meantime, EAAC1 was consumed and the EAAC1 expression was reduced. Conversely, the EAAC1 expression in the ileum was reduced, leading to lower Glu transport efficiency. The content of free Glu in the ileum was reduced in the weaned piglets compared with the suckling piglets. It is of note that the Glu content is not solely determined by transport, but also by the Glu-Gln cycle.

In conclusion, the present study determined that EAAC1 expression was reduced in the jejunum of the weaned piglets and the consumed EAAC1 was associated with the increased transport of Glu in the jejunum of the weaned piglets. Therefore, the content of amino acids such as Glu was increased in the jejunum. This was accompanied by the reduced expression of GTRAP3-18, the regulator of EAAC1. As EAAC1 expression was downregulated in the ileum of the weaned piglets, the Glu transport rate was reduced, leading to reduction of amino acid content, such as Glu in the ileum.

\section{Acknowledgements}

The present study was supported by the China Postdoctoral Science Foundation (grant no. 2013M531011) and the Heilongjiang Province Natural Science Foundation of China (grant nos. C201444 and C2015040).

\section{References}

1. Ruth MR and Field CJ: The immune modifying effects of amino acids on gut-associated lymphoid tissue. J Anim Sci Biotechnol 4: 27, 2013.

2. Bianchi MG, Bardelli D, Chiu M and Bussolati O: Changes in the expression of the glutamate transporter EAAT3/EAAC1 in health and disease. Cell Mol Life Sci 71: 2001-2015, 2014.

3. Aoyama K and Nakaki T: Neuroprotective properties of the excitatory amino acid carrier 1 (EAAC1). Amino Acids 45: 133-142, 2013.

4. Butchbach ME, Lai L and Lin CL: Molecular cloning, gene structure, expression profile and functional characterization of the mouse glutamate transporter (EAAT3) interacting protein GTRAP3-18. Gene 292: 81-90, 2002.

5. Aoyama K and Nakaki T: Inhibition of GTRAP3-18 may increase neuroprotective glutathione (GSH) synthesis. Int J Mol Sci 13: 12017-12035, 2012.

6. Jang BG, Won SJ, Kim JH, Choi BY, Lee MW, Sohn M, Song HK and Suh SW: EAAC1 gene deletion alters zinc homeostasis and enhances cortical neuronal injury after transient cerebral ischemia in mice. J Trace Elem Med Biol 26: 85-88, 2012.

7. Aoyama K, Watabe M and Nakaki T: Modulation of neuronal glutathione synthesis by EAAC1 and its interacting protein GTRAP3-18. Amino Acids 42: 163-169; 2012.

8. Berman AE, Chan WY, Brennan AM, Reyes RC, Adler BL, Suh SW, Kauppinen TM, Edling Y and Swanson RA: $\mathrm{N}$-acetylcysteine prevents loss of dopaminergic neurons in the EAAC1-/- mouse. Ann Neurol 69: 509-520, 2011

9. Duerson K, Woltjer RL, Mookherjee P, Leverenz JB, Montine TJ, Bird TD, Pow DV, Rauen T and Cook DG: Detergent-insoluble EAAC1/EAAT3 aberrantly accumulates in hippocampal neurons of Alzheimer's disease patients. Brain Pathol 19: 267-278, 2009.

10. Fu D, Yang H, Kong X, Blachier F, Wang W and Yin Y: Molecular cloning and expression profiling of excitatory amino acid carrier 1 in suckling Huanjiang mini-piglets with large or small body weight at birth. Mol Biol Rep 40: 3341-3350, 2013.

11. Bregendahl K, Yang X, Liu L, Yen JT, Rideout TC, Shen Y Werchola $\mathrm{G}$ and Fan MZ: Fractional 485 protein synthesis rates are similar when measured by intraperitoneal or intravenous flooding 486 doses of L-[ring-2H5]phenylalanine in combination with a rapid regimen of sampling in piglets. J Nutr 138: 1976-1981, 2008

12. Livak KJ and Schmittgen TD: Analysis of relative gene expression data using real-time quantitative PCR and the 2(-Delta Delta C(T)) method. Methods 25: 402-408, 2001.

13. Thiele B, Stein N, Oldiges M and Hofmann D: Direct analysis of underivatized amino acids in plant extracts by LC-MS-MS. Methods Mol Biol 828: 317-328, 2012.

14. Takita M and Kikusui T: Early weaning influences short-term synaptic plasticity in the medial prefrontal-anterior basolateral amygdala pathway. Neurosci Res 103: 48-53, 2006. 
15. Xiong X, Yang H, Tan B, Yang C, Wu M, Liu G, Kim SW, Li T, Li L, Wang J, et al: Differential expression of proteins involved in energy production along the crypt-villus axis in early-weaning pig small intestine. Am J Physiol Gastrointest Liver Physiol 309: G229-G237, 2015.

16. Candeias EM, Sebastião IC, Cardoso SM, Correia SC, Carvalho CI, Plácido AI, Santos MS, Oliveira CR, Moreira PI and Duarte AI: Gut-brain connection: The neuroprotective effects of the anti-diabetic drug liraglutide. World J Diabetes 6: 807-827, 2015

17. Gu X, Li D and She R: Effect of weaning on small intestinal structure and function in the piglet. Arch Tierernahr 56: 275-286, 2002.

18. Watabe M, Aoyama K and Nakaki T: A dominant role of GTRAP3-18 in neuronal glutathione synthesis. J Neurosci 28: 9404-9413, 2008.
19. Lin CI, Orlov I, Ruggiero AM, Dykes-Hoberg M, Lee A, Jackson M and Rothstein JD: Modulation of the neuronal glutamate transporter EAAC1 by the interacting protein GTRAP3-18. Nature 410: 84-88, 2001.

20. Burrin DG and Stoll B: Metabolic fate and function of dietary glutamate in the gut. Am J Clin Nutr 90: 850S-856S, 2009.

21. Fan MZ, Matthews JC, Etienne NM, Stoll B, Lackeyram D and Burrin DG: Expression of apical membrane L-glutamate transporters in neonatal porcine epithelial cells along the small intestinal crypt-villus axis. Am J Physiol Gastrointest Liver Physiol 287: G385-G398, 2004. 